\title{
Methodological challenges designing pragmatic, multi-centre randomised controlled trials in critical care
}

\author{
Graeme MacLennan*, Marion Campbell, John Norrie \\ From 2nd Clinical Trials Methodology Conference: Methodology Matters \\ Edinburgh, UK. 18-19 November 2013
}

Researchers designing pragmatic, multi-centre randomised controlled trials (RCTs) in critical care are faced with numerous potential methodological challenges. These challenges can be outlined using PICO terminology:

\section{Population}

Unlike many other clinical areas, patients admitted to intensive care units (ICUs) do not have easily identifiable diseases (e.g. diabetes or cancer), but are classified as having syndromes with hazy definitions that may be inconsistently applied both within and between centres. The definition and implementation of inclusion and exclusion criteria is therefore difficult, resulting in clinically heterogeneous populations.

\section{Intervention and control}

Due to the rapidly declining condition of patients in ICU "treatment as usual" consists of many therapies that can vary both within and between centres. Often, control and experimental care are complex interventions with minimal differences between treatment protocols and there is a risk of treatment contamination due to creep from control to intervention treatment, particularly when blinding is not feasible. Protocolising control group treatment is essential but non-compliance may be frequent.

\section{Outcome}

The gold standard outcome in critical care research is all-cause mortality reduction. However, ICU patients often have multiple life threatening conditions and RCTs require large sample sizes due to small anticipated effect sizes of interventions on mortality. Alternative

University of Aberdeen, Aberdeen, UK

(c) 2013 MacLennan et al; licensee BioMed Central Ltd. This is an Open Access article distributed under the terms of the Creative Commons Attribution License (http://creativecommons.org/licenses/by/2.0), which permits unrestricted use, distribution, and reproduction in any medium, provided the original work is properly cited. outcomes used are composite or combined outcomes. Composite outcomes may be difficult to interpret and combined outcomes, e.g. ventilator free days, pose analysis challenges.

We will discuss the trade-offs between pros and cons of potential solutions to the problems outlined above.

Published: 29 November 2013

doi:10.1186/1745-6215-14-S1-0125

Cite this article as: MacLennan et al:: Methodological challenges designing pragmatic, multi-centre randomised controlled trials in critical care. Trials 2013 14(Suppl 1):0125.

Submit your next manuscript to BioMed Central and take full advantage of:

- Convenient online submission

- Thorough peer review

- No space constraints or color figure charges

- Immediate publication on acceptance

- Inclusion in PubMed, CAS, Scopus and Google Scholar

- Research which is freely available for redistribution 